\title{
Linfoma não-Hodgkin de órbita: relato de caso
}

\author{
Non-Hodgkin orbital lymphoma: case report
}

\author{
Cristiane do Prado Silva ${ }^{1}$ \\ Maria Aparecida Doming Des $^{2}$ \\ Silvana Artioli Schellini ${ }^{3}$ \\ Ligia Niero ${ }^{4}$
}

Trabalho realizado na Faculdade de Medicina de Botucatu - UNESP.

${ }^{1}$ Residente do Departamento de Oftalmologia, Otorrinolaringologia e Cirurgia de Cabeça e Pescoço da Faculdade de Medicina de Botucatu - Universidade Paulista - UNESP - Botucatu (SP) - Brasil.

${ }^{2}$ Professora Doutora do Departamento de Patologia, Faculdade de Medicina de Botucatu da UNESP - Botucatu (SP) - Brasil.

${ }^{3}$ Livre-Docente do Departamento de Oftalmologia, Otorrinolaringologia e Cirurgia de Cabeça e Pescoço da Faculdade de Medicina de Botucatu da UNESP Botucatu (SP) - Brasil.

${ }^{4}$ Professora Doutora do Departamento de Clínica Médica, Faculdade de Medicina de Botucatu da UNESP Botucatu (SP) - Brasil.

Endereço para correspondência: Silvana Artioli Schellini. DEP. OFT/ORL/CCP - Faculdade de Medicina de Botucatu - UNESP - CEP 18618-000 - Botucatu - SP E-mail: sartioli@fmb.unesp.br

Recebido para publicação em 14.12.2006

Última versão recebida em 12.07.2007

Aprovação em 06.12.2007

\section{RESUMO}

O objetivo é relatar manifestação incomum de linfoma não-Hodgkin de órbita. Paciente masculino, de 75 anos, se apresentou com queixa de lacrimejamento crônico bilateral. Havia feito dacriocistorrinostomia endonasal à direita e à esquerda por duas vezes, sem sucesso. Ao exame, massas de consistência fibroelástica, em topografia das "bolsas" de gordura das pálpebras inferiores e proptose axial. O paciente negava outros sintomas ou sinais sistêmicos. Hemograma sem alteração, hormônios tireoidianos normais. A tomografia computadorizada mostrava infiltrado difuso na órbita e proptose axial. Biópsia de gordura orbitária e de medula óssea diagnosticaram linfoma não-Hodgkin. O paciente foi tratado com quimioterapia, sendo em seguida submetido à cirurgia da via lacrimal bilateral, com resolução do quadro. A doença sistêmica que exigia diagnóstico e tratamento adequados para que se tivesse bom prognóstico estava mascarada pelo quadro de epífora bilateral.

Descritores: Linfoma não-Hodgkin; Linfoma de pequenas células; Leucemia linfocítica Órbita; Neoplasias orbitárias; Masculino; Idoso; Relatos de casos [tipos de publicação]

\section{INTRODUÇÃO}

Os linfomas não-Hodgkin (LNH) constituem um grupo de neoplasias muito heterogêneo, podendo derivar de proliferação clonal de linfócitos $\mathrm{T}$ e B. Esses tumores podem aparecer em nódulos linfáticos e sítios extranodais $^{(1)}$.

A órbita é um sítio raro dessa doença, estimando-se que nela ocorra apenas 1 a $8 \%$ dos $\mathrm{LNH}^{(1-5)}$.

Apesar dos linfomas representarem aproximadamente $10 \%$ de todos os tumores primários da órbita, o acometimento orbitário por linfoma sistêmico ocorre em apenas $1,5 \%$ dos $\operatorname{casos}^{(2)}$.

O caso aqui apresentado é de um portador de LNH sistêmico com acometimento orbitário bilateral, em que o diagnóstico da neoplasia foi feito a partir de sinais e sintomas oculares.

\section{RELATO DO CASO}

Paciente de 75 anos, masculino, branco, agricultor, compareceu ao Serviço de Oftalmologia do Hospital de Clínicas da Faculdade de Medicina de Botucatu (UNESP) no ano de 2002, com queixa de lacrimejamento bilateral e bolsas de gordura proeminentes.

Como antecedentes oculares, referia ter feito blefaroplastia inferior pelas bolsas proeminentes, sem melhora e dacriocistorrinostomia endonasal bilateral por duas vezes, continuando a apresentar epífora. O paciente 
negava queixas sistêmicas associadas, exceto ter feito tratamento anterior para hipotireoidismo.

Ao exame externo, notava-se proptose leve, bolsas de gordura bastante pronunciadas e esclera aparente bilateral (Figura 1). À palpação, as bolsas de gordura tinham consistência fibroelástica e eram indolores. O teste de desaparecimento da fluoresceína (Teste de Zappia-Milder) era positivo em ambos os olhos, sem refluxo à expressão do saco lacrimal. No restante do exame ocular não se observaram alterações, assim como não foram verificadas linfadenomegalias.

Na tomografia computadorizada de órbita observou-se infiltração difusa dos tecidos orbitários bilateralmente, principalmente na região retro-ocular, sem contornos definidos, associada à proptose axial (Figuras 2 e 3 ).

O hemograma era normal, assim como os hormônios tireoidianos (TSH= 4,02 ng/dl; T4 Livre= 1,49 ng/ml).

A biópsia de gordura orbitária à direita revelou se tratar de linfoma linfocítico/leucemia linfocítica crônica (LL/LLC) (estudo imunohistoquímico: CD20+; CD5+; CD23+) (Figuras 4 e 5).

Posteriormente foi puncionada a medula óssea, revelando que havia acometimento por LL/LLC.

Pelo acometimento de órbita e medula óssea, sem que houvesse febre, perda de peso e/ou suores noturnos o estadiamento foi IVa.

Realizado quimioterapia (COP - 8 ciclos), com boa evolução do quadro.

O paciente continuou com a epífora bilateral, tendo sido confirmada a obstrução usando dacriocistografia com contraste oleoso (Lipiodol ${ }^{\circledR}$, Guerbet) que apontou para obstrução baixa bilateral, com saco lacrimal não dilatado. A conduta foi dacriocistorrinostomia (DCR) externa bilateral, com intubação das vias lacrimais.

Atualmente o paciente encontra-se bem, tendo ocorrido melhora considerável dos sintomas, mantendo ainda tratamento quimioterápico (Leukeran ${ }^{\circledR} 4 \mathrm{~g} /$ dia) (Figura 6).

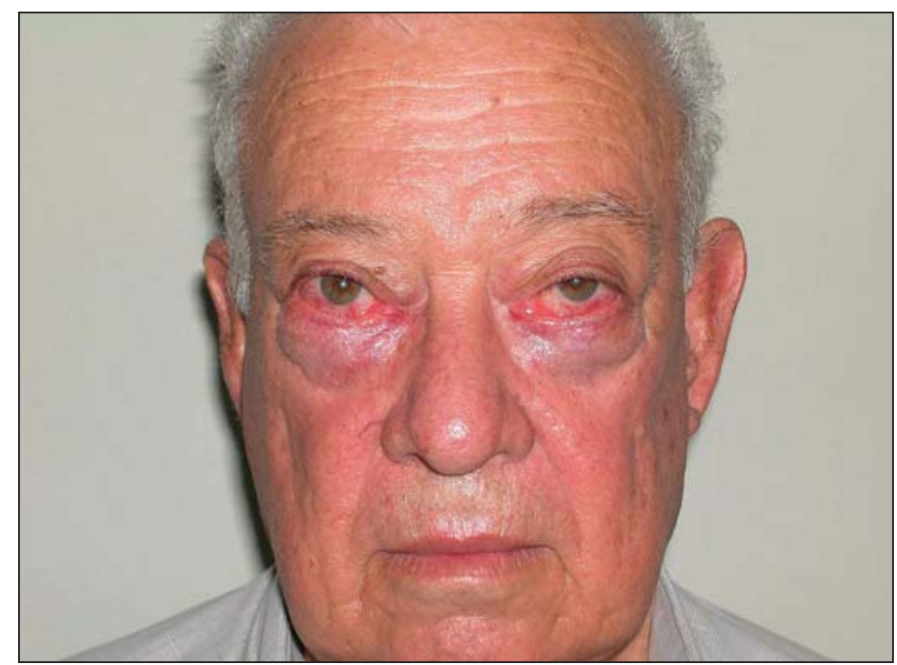

Figura 1 - O paciente apresentava aumento de bolsões de gordura proptose leve e esclera aparente bilateralmente (ao ser inicialmente examinado)

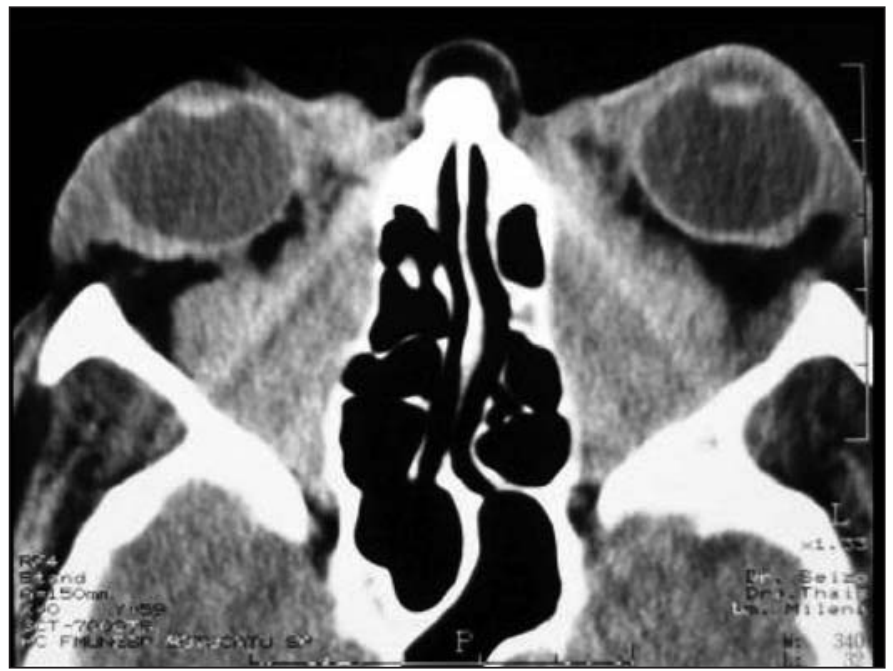

Figura 2 - Tomografia computadorizada demonstrando proptose discreta e infiltrado difuso nos tecidos orbitários em ambos os olhos

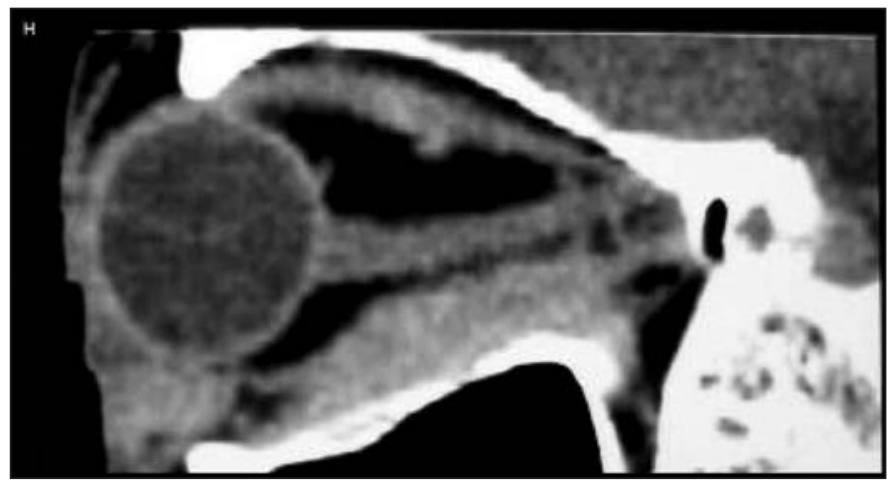

Figura 3 - Tomografia computadorizada mostrando infiltração orbitária

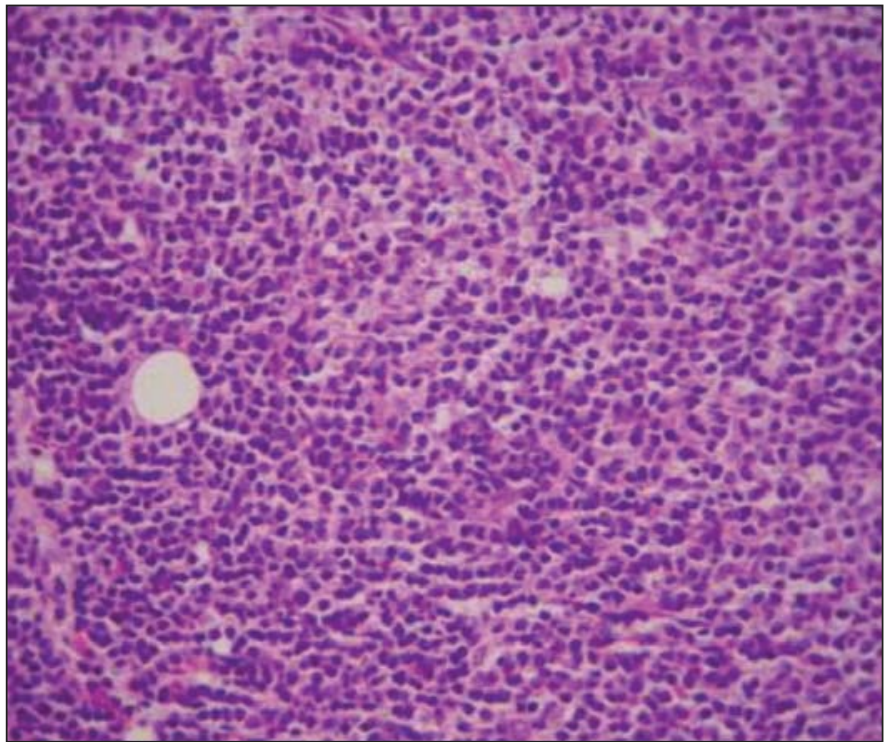

Figura 4 - Corte histológico da gordura orbitária revelando proliferação de linfócitos pequenos 


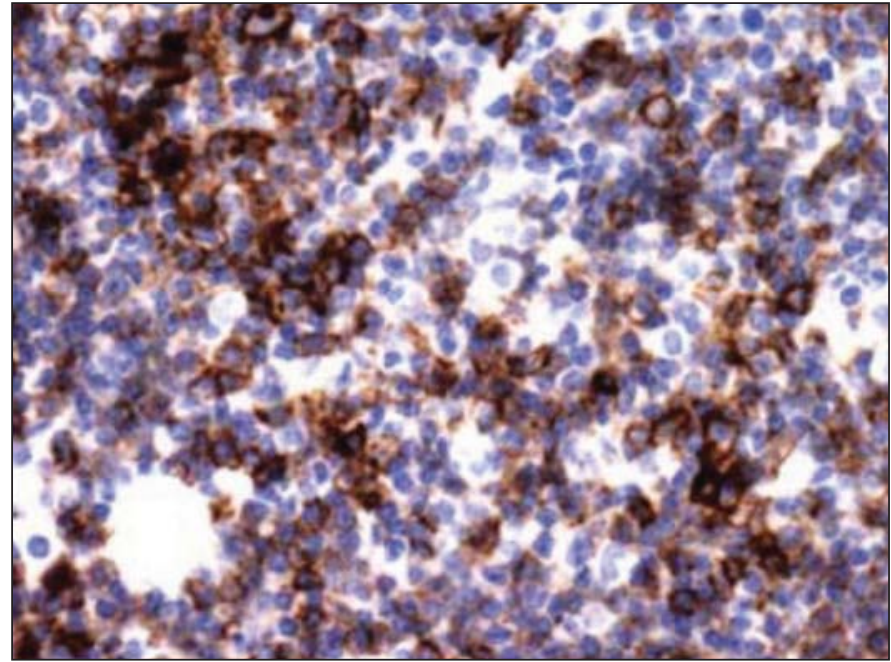

Figura 5 - Linfócitos imuno-expressam o marcador $\mathrm{CD}_{20}$ e co-expressam $\mathrm{CD}_{5}$ e $\mathrm{CD}_{23}$ revelando o diagnóstico de LL/LLC

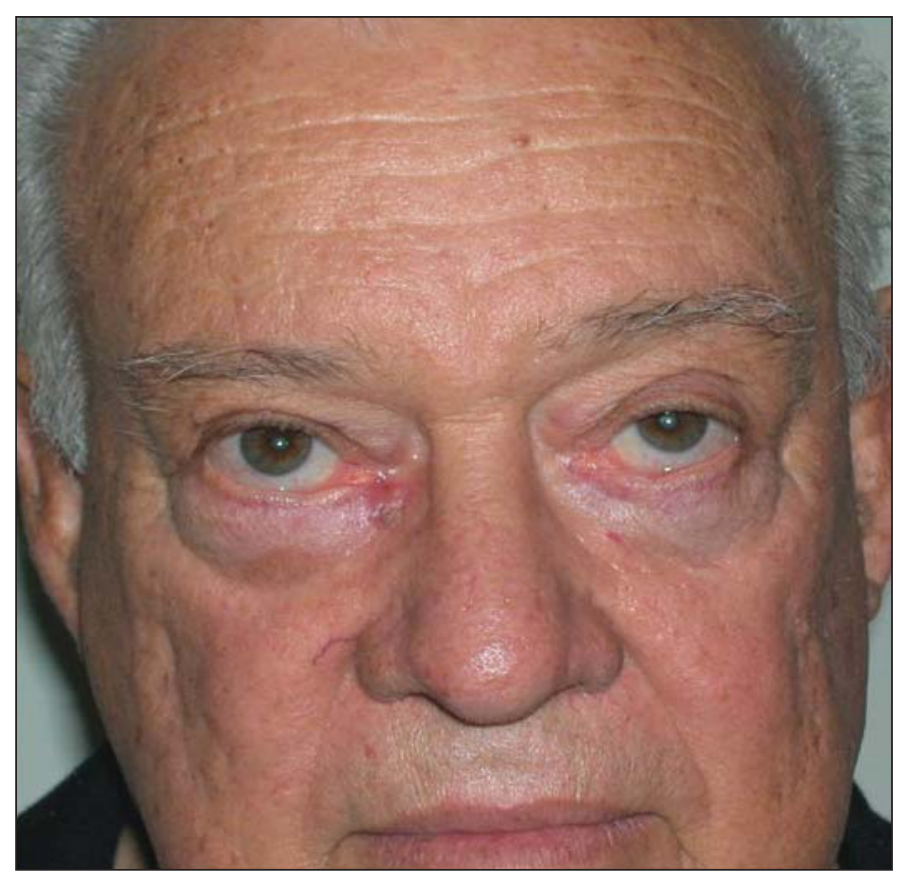

Figura 6 - Redução dos bolsões palpebrais após quatro meses de quimioterapia

\section{DISCUSS ÃO}

O paciente apresentado é masculino, de 75 anos, perfil que está de acordo com a literatura que aponta LNH preferentemente entre a $5^{\underline{a}}$ e a $7^{\underline{a}}$ décadas de vida ${ }^{(4-5)}$, apesar de afetar mais mulheres que homens $(1,5 \text { a } 2 q: 1 \zeta)^{(4)}$.

Quando são tumores primários, ocorrem com maior frequiência na órbita, seguindo-se de conjuntiva, pálpebras, glândula lacrimal e carúncula ${ }^{(6)}$.

A maioria dos LNH são originados de células do tipo $\mathrm{B}^{(4,7)}$, assim como o caso aqui relatado, tendo sido a órbita acometida secundariamente à doença sistêmica.

Epífora, a queixa que trouxe o paciente para o serviço, é um sintoma pouco freqüente ${ }^{(6)}$. Os sinais mais observados são hiperemia conjuntival, proptose e massa orbital ${ }^{(1,6)}$. A massa orbital no paciente em questão era evidenciada como "bolsões" de gordura nas pálpebras inferiores, dos quais diferia pela consistência apresentada, sendo muito mais endurecida, embora tenha sido confundido com bolsas e, inclusive, operado.

O paciente aqui relatado apresentava envolvimento orbitário bilateral, o que é comum quando a órbita é acometida secundariamente à doença sistêmica; o acometimento bilateral nos linfomas primários de órbita ocorre em apenas 10 a $17 \%$ dos $\operatorname{casos}^{(1,4)}$.

A inexistência de sintomas sistêmicos no momento do exame (febre, perda de peso e/ou suores noturnos) é frequiente nos tumores orbitários localizados, (1) podendo estar ausentes também quando há acometimento sistêmico ${ }^{(8)}$.

A tomografia computadorizada de órbita revelou infiltração difusa dos tecidos orbitários, aspecto que fala a favor de linfoma. Apesar da tomografia auxiliar no diagnóstico, o exame histológico é o que define o quadro, tendo a biópsia da gordura orbitária revelado LL//LLC, mais especificamente um subtipo que constitui o grupo de baixo grau (classificação Working formulation $)^{(7,9)}$, posteriormente também detectado pela biópsia da medula óssea.

Esse subtipo de LNH é uma neoplasia constituída de linfócitos pequenos, bem diferenciados, com núcleos hipercorados que imuno-expressam $\mathrm{CD}_{20}$ (marcador de neoplasias de linhagem do tipo B) e usualmente co-expressam $\mathrm{CD}_{5}$ e $\mathrm{CD}_{23}^{(8,10)}$. Juntamente com o quadro clínico e os dados do hemograma, a imuno-fenotipagem é a principal avaliação diagnóstica e permite o diagnóstico diferencial com as outras síndromes linfoproliferativas ${ }^{(8,10)}$.

A LLC e o LL são praticamente a mesma doença ${ }^{(11)}$. Se há células neoplásicas no sangue periférico (linfocitose) fala-se em LLC. Se não, considera-se como LL ${ }^{(11)}$. Como o paciente não apresentava alteração do hemograma, foi classificado como portador de LL. Esse subtipo é considerado um linfoma indolente que acomete especialmente idosos, sendo raro nos jovens. Geralmente ao diagnóstico já se encontra disseminado, com grande chance de acometimento medular ${ }^{(9,11)}$.

A avaliação de 145 casos de linfoma com envolvimento intra-ocular e de anexos, mostrou que a maioria dos casos corresponde a linfoma MALT ou linfoplasmocítico (36 e 22\%, respectivamente). Já o subtipo LL/LLC (o diagnosticado neste caso) foi visto em apenas $10 \%$ destes resultados ${ }^{(1)}$. Talvez, uma ocorrência mais baixa do LL/LLC na órbita seja devido ao fato de que este subtipo seja causador principalmente de doença sistêmica, estando a órbita envolvida secundariamente.

Vários são os parâmetros que influenciam no curso clínico dos portadores de linfoma de anexos, tais como a localização anatômica, o estágio no diagnóstico, o subtipo histológico e associação com doença sistêmica, havendo outros para os 
quais estas considerações não foram significativas para determinar o prognóstico do paciente ${ }^{(5)}$.

O tratamento dos linfomas de anexos orbitários pode ser feito usando radioterapia, quimioterapia e/ou exérese do tumor (dependendo da sua localização). O LL/LLC possui curso clínico indolente e pode não apresentar uma boa resposta à quimioterapia (por apresentar baixa proliferação) ${ }^{(11)}$. Em alguns casos pode-se até considerar conduta expectante (avaliando a massa tumoral e a idade do paciente, já que acomete preferencialmente idosos ${ }^{(11)}$. No caso apresentado optou-se por tratamento quimioterápico (COP-ciclofosfamida, Oncovin $^{\circledR}$ e prednisona) e o paciente evoluiu bem.

A causa da epífora no presente paciente poderia ter sido a compressão da via lacrimal excretora pelos tecidos infiltrados pelo linfoma. As intervenções anteriores ou a compressão extrínseca mantida podem ter levado a obstrução verdadeira, resultando na necessidade de intervenção cirúrgica. Optou-se pela intubação com fio de silicone, tendo em vista as pequenas dimensões do saco lacrimal, com resolução da epífora.

É relatado um portador de LL/LLC com acometimento orbitário secundário, descoberto a partir de queixas oftalmológicas, como a epífora e "bolsões" nas pálpebras inferiores. São ressaltados os aspectos clínicos, com ênfase no diagnóstico e o tratamento do paciente em questão.

\section{ABSTR ACT}

The purpose is to report an unusual case of orbital nonHodgkin lymphoma. A 75-year-old man presented with bilateral chronic epiphora complaint and inferior eyelid tumors, axial proptosis, without previous systemic manifestation. The patient was submitted to bilateral endonasal dacryocystorhinostomy twice and the epiphora complaint persisted. The inferior eyelid and bone marrow biopsy revealed non-Hodgkin lymphoma. The patient was treated with systemic chemotherapy and dacryocystorhinostomy with good resolution. The precise diagnosis and the treatment were very important to reach a good resolution of the bilateral epiphora complaint.

Keywords: Lymphoma, non-Hodgkin; Lymphoma, small-cell; Leukemia, lymphocytic; Orbit; Orbital neoplasms; Male; Aged; Case reports [publication type]

\section{REFERÊNCIAS}

1. Meunier J, Lumbroso-Le Rouic L, Vincent-Salomon A, Dendale R, Asselaim $\mathrm{B}$, Arnaud $\mathrm{P}$, et al. Ophthalmologic and intraocular non-Hodgkin's lymphoma: a large single centre study of initial characteristics, natural history and prognostic factors. Hematol Oncol. 2004;22(4):143-58.

2. Albuquerque AP, Aguni JS, Correia RJ, Vegini F, Souza AD. Linfoma de células da zona do manto em anexos oculares: relato de caso. Arq Bras Oftalmol. 2006; 69(3):421-5.

3. Fung CY, Tarbell NJ, Lucarelli MJ, Goldberg SI, Linggood RM, Harris NL, et al. Ocular adnexal lymphoma: clinical behavior of distinct World Health Organization classification subtypes. Int J Radiat Oncol Biol Phys. 2003;57(5): 1382-91.

4. Couplant SE, Hummel M, Stein H. Ocular adnexal lymphomas: five case presentations and a review of the literature. Surv Ophthalmol. 2002;47(5): 470-90.

5. Auw-Haedrich C, Coupland SE, Kapp A, Schmitt-Graff A, Buchen R, Witschel H. Long term outcome of ocular adnexal lymphoma subtype according to the REAL classification. Revised European and American Lymphoma. Br J Ophthalmol. 2001;85(1):63-9.

6. Couplant SE, Krause L, Delecluse HJ, Anagnostopoulos I, Foss HD, Hummel M, et al. Lymphoproliferative lesions of the ocular adnexa. Analysis of 112 cases. Ophthalmology. 1998;105(8):1430-41.

7. Jakobiec FA, McLean I, Font RL. Clinicopathologic characteristics of orbital lymphoid hyperplasia. Ophthalmology. 1979;86(5):946-66.

8. Müller-Hermelink HK, Catovsky D, Montserrat E, Harris NL. Chronic lymphocytic leukaemia/small lymphocytic lymphoma. In: Jaffe ES, Harris NL, Stein H, Vardiman JW, editors. World Health Organization. classification of tumours. Pathology and genetics of tumours of haematopoietic and lymphoid Tissues. Lyon: IARC Press; 2001. p.127-30.

9. Shipp MA, Harris NL. Linfomas não-Hodgkin. In: Goldman L, Bennett JC, editors. Cecil Tratado de Medicina Interna. Rio de Janeiro: Guanabara Koogan; 2001. p.1069-77.

10. Lorant-Metze I. LLC: critérios diagnósticos, imunofenotipagem e diagnóstico diferencial. Rev Bras Hematol Hemoter. 2005;27(4):233-5.

11. Universidade Estadual de Campinas. Departamento de Anatomia Patológica. Anatomia Patológica para Graduação. Leucemia linfóide crônica ou linfoma linfocítico [Internet]. Campinas: UNICAMP. [citado 2007 set 15]. Disponível em: http://anatpat.unicamp.br/lamhemo7.html 